\title{
Perfil dos gestores de esporte e lazer dos municípios do território de identidade litoral sul da Bahia
}

\section{RESUMO}

O objetivo deste estudo foi apresentar e analisar o perfil dos gestores responsáveis pelo esporte e lazer de 15 municípios do Território de Identidade Litoral Sul da Bahia, buscando gerar reflexões em torno das possibilidades de desenvolvimento das políticas públicas da região. A coleta de dados foi realizada por meio de um questionário virtual utilizando o Google Formulários, em um primeiro momento, e posteriormente in loco. Como resultado, os dados apontaram para a necessidade de se discutir a importância da capacitação/especialização dos gestores no que tange ao fomento ao lazer e ao esporte, compreendidos nesta pesquisa como direitos do cidadão e, portanto, objetos de uma consistente e regular política pública para os municípios da região.

PALAVRAS-CHAVE: Esporte; Lazer; Políticas públicas; Litoral sul da bahia

\section{Marco Aurélio Ávila}

Doutorado em Turismo e Desenvolvimento Sustentável, ULPGC, Espanha Universidade Estadual de Santa Cruz, Ilhéus- BA, Brasil mavila1000@gmail.com http://orcid.org/0000-0001-9162-2873

Cristiano de Sant Anna Bahia Doutorado em Educação Física, Universidade Federal de Santa Catarina

Universidade Estadual de Santa Cruz, Ilhéus- BA, Brasil csbahia@uesc.br

D https://orcid.org/0000-0001-7599-6250

Felipe Eduardo Ferreira Marta

Doutorado em História, PUC-SP

Universidade Estadual do Sudoeste da Bahia (PPGMLS/UESB)

Universidade Estadual de Santa Cruz, Ilhéus- BA, Brasil fefmarta@uesc.br

https://orcid.org/0000-0002-0501-4298

Carla Carolina Venâncio Dos Santos

Graduanda em Educação Física Universidade Estadual de Santa Cruz, Ilhéus- BA, Brasil carol10@hotmail.com

https://orcid.org/0000-0001-9245-1703

Lucas Menezes Amaral Levita Graduando em Educação Física Universidade Estadual de Santa Cruz, Ilhéus- BA, Brasil lucaslevita7@hotmail.com https://orcid.org/0000-0001-8230-8428 
Profile of sport and leisure managers in the municipalities of the southern coastal identity territory of Bahia

\begin{abstract}
The aim of this study was to present and analyze the profile of managers responsible for sports and leisure in 15 municipalities in the Southern Coastal Identity Territory of Bahia, seeking to generate reflections on the possibilities of developing public policies in the region. Data collection was performed through a virtual questionnaire using Google Forms, at first, and in loco. As a result, the data pointed to the need to discuss the importance of training/specialization of managers in terms of promoting leisure and sport, understood in this research as citizens' rights and therefore, objects of a consistent and regular public policy for municipalities in the region.
\end{abstract}

KEYWORDS: Sport; Leisure; Public politics; South coast of bahia

\title{
Perfil de los gestores deportivos de los municipios del territorio de identidad litoral sur de Bahía
}

\section{RESUMEN}

El objetivo de este estudio fue presentar y analizar el perfil de los gestores responsables por el sector de deporte y ocio en 15 municipios del Territorio de Identidad Litoral Sur de Bahía, buscando generar reflexiones sobre las posibilidades de desarrollo de políticas públicas en la región. Para ello, la recogida de datos se realizó inicialmente mediante un cuestionario virtual en Google Forms, y después, en el sitio. Como resultado, los datos señalaron a la necesidad de discutir la importancia de la formación/capacitación de los gestores respeto a la promoción del ocio y del deporte, entendidos en esta investigación como pautas de ciudadanía y, por consiguiente, que deben ser objeto de una coherente y regular política pública para los municipios de la región.

PALABRAS-CLAVE: Deporte; Ocio; Políticas públicas; Litoral sur de bahía 


\section{INTRODUÇÃO}

O reconhecimento do esporte e do lazer como direitos sociais garantidos na Constituição Federal Brasileira de 1988 (BRASIL, 1998) representou um avanço no que se refere ao amparo legal desses temas. Entretanto, esses setores tradicionalmente se apresentam hierarquizados em relação aos outros direitos, evidenciando que ainda não existe uma política de Estado que os garantam como direitos (SANTOS; AMARAL, 2010; ATHAYDE; MASCARENHAS; SALVADOR, 2015).

No que tange às políticas públicas postas em prática no Brasil, nas décadas de 1950 e 1960, o Estado possuía o direcionamento das ações voltadas ao esporte, fomentando assim o aumento da inserção deste fenômeno na sociedade, em especial nos espaços escolares, sendo utilizadas enquanto aparelho ideológico do Estado, no intuito de fomentar as práticas esportivas com características de rendimento (LINHALES, 1997; MEZZADRI; SILVA; FIGUERÔA 2015)

Além disso, do ponto de vista da implementação de ações e políticas públicas de esporte e de lazer, vários órgãos foram criados em diversos espaços e tempos, no Brasil, sendo alvo de críticas históricas e incoerências institucionais que iam desde a precarização de espaços públicos de esporte e de lazer até políticas eficazes e inclusivas (BETTIN; PEIL; MELO, 2018). Neste cenário, pode-se citar a Divisão de Educação Física do Ministério da Educação e Cultura do Esporte no Brasil, em 1937, com a Lei $n^{\circ} 378$, de 13/03/37; a separação do Ministério do Esporte da pasta do Turismo, em 2003; e a inclusão do Ministério do Esporte, em 2019, no Ministério da Cidadania, como Secretaria Especial do Esporte (CARNEIRO; ATHAYDE; MASCARENHAS, 2019).

Várias ações foram implementadas durante a existência do Ministério do Esporte, desde 2003, relacionadas ao esporte e lazer, como: Programa Segundo Tempo, Programa Lazer Segundo Tempo; Segundo Tempo no Mais Educação; Recreio nas Férias; Esporte e Lazer na Cidade; Competições e Eventos; Prêmio Brasil de Esporte; Rede CEDES; Jogos Indígenas; Pintando a Liberdade, entre outras (BRASIL, 2020).

Essas ações de esporte e de lazer foram descentralizadas para os diversos municípios do Brasil, no entanto não foram efetivadas como políticas públicas que materializassem a democratização e universalização do esporte e do lazer (EVERTON; MATIAS, 2017). Nesse contexto, vários estudiosos estão desenvolvendo pesquisas sobre as políticas públicas com o esporte e o lazer e suas repercussões no cenário da gestão e democratização de acesso, entendidos enquanto direitos sociais preestabelecidos pela Constituição Federal (AMARAL; RIBEIRO; SILVA, 2014). 
Desta forma, considerando a relevância desses setores para a sociedade, o presente estudo buscou apresentar e analisar o perfil de 15 gestores municipais responsáveis pelo esporte e lazer entre os 26 municípios que fazem parte do Território de Identidade Litoral Sul da Bahia.

\section{MÉTODO}

A abordagem metodológica utilizada foi quanti-qualitativa, por meio de um estudo exploratório/descritivo com objetivo de proporcionar uma maior familiaridade com o problema, com vistas a torná-lo mais explícito (GIL, 2010). Tal abordagem foi usada para conhecer o delineamento do perfil dos gestores.

O contexto de investigação foi o Território de Identidade Litoral Sul que corresponde a 2,6\% do território estadual, composto administrativamente por 26 municípios: Almadina, Arataca, Aurelino Leal, Barro Preto, Buerarema, Camacã, Canavieiras, Coaraci, Floresta Azul, Ibicaraí, Ilhéus, Itabuna, Itacaré, Itaju do Colônia, Itajuípe, Itapé, Itapitanga, Jussari, Maraú, Mascote, Pau-Brasil, Santa Luzia, São José da Vitória, Ubaitaba, Una e Uruçuca (BAHIA, 2015). Dados com a área e a população dos municípios investigados são apresentados na Tabela 1.

Tabela 1 - Área de população dos 15 municípios que participaram da pesquisa

\begin{tabular}{c|c|c}
\hline Município & Área $\left(\mathbf{K m}^{\mathbf{2}}\right)$ & População (habitantes) \\
\hline Almadina & 251,1 & 6.357 \\
\hline Arataca & 375,2 & 10.392 \\
\hline Barro Preto & 128,4 & 6.453 \\
\hline Buerarema & 230,5 & 18.605 \\
\hline Camacã & 626,7 & 31.472 \\
\hline Canavieiras & $1.327,0$ & 32.336 \\
\hline Coaraci & 282,6 & 20.964 \\
\hline Ibicaraí & 231,9 & 24.272 \\
\hline Ilhéus & $1.760,0$ & 184.236 \\
\hline Itabuna & 432,2 & 204.667 \\
\hline Itacaré & 737,9 & 24.318 \\
\hline Itajuípe & 284,5 & 21.081 \\
\hline Pau-Brasil & 606,5 & 10.852 \\
\hline Ubaitaba & 178,8 & 20.691 \\
\hline Una & $1.177,5$ & 24.110
\end{tabular}

Fonte: BAHIA. Perfil dos Territórios de Identidade/Superintendência de Estudos Econômicos e Sociais da Bahia. Salvador: SEI (2015).

Para obtenção dos dados, foi utilizado um questionário, dividido em duas partes, contendo 65 perguntas que foram respondidas pelos gestores municipais responsáveis pelo setor de esporte e lazer nos municípios ou por funcionário indicado por eles. 
As coletas foram realizadas entre 17 de outubro de 2017 e 12 de fevereiro de 2019 ( $1^{\text {a }}$ etapa - on-line) e entre 9 de dezembro de 2019 e 22 de janeiro de 2020 ( $2^{\text {a }}$ etapa - presencial). Na primeira etapa, os convites foram enviados por e-mail, solicitando a participação mediante o preenchimento de um questionário virtual desenvolvido na plataforma Google Formulários. Nessa etapa, 9 questionários foram respondidos por representantes dos seguintes municípios: Almadina, Arataca, Camacã, Coaraci, Ilhéus, Itabuna, Itacaré, Pau-Brasil e Una. Em função das dificuldades de retorno nesse procedimento de coleta por parte dos representantes dos municípios, optamos por realizar a coleta presencial.

Assim, na segunda etapa, 6 questionários foram respondidos presencialmente por representantes dos seguintes municípios: Barro Preto, Buerarema, Canavieiras, Ibicaraí, Itajuípe e Ubaitaba, totalizando 15 municípios participantes do estudo.

Todos os protocolos da pesquisa aconteceram com base nos trâmites do Comitê de Ética em Pesquisa com Seres Humanos da Universidade Estadual de Santa Cruz, sob o número CAEE: 71324717.0 .0000 .5526 .

O tratamento dos dados foi realizado a partir da codificação/classificação das respostas que estão apresentadas na Tabelas 2; para isso, foram utilizados os artifícios da estatística descritiva, como frequência e percentuais. Paralelamente, foi realizada a análise das variáveis e suas inter-relações com a base teórica, utilizando-se os métodos descritivo e explicativo para conhecimento dos fenômenos e suas relações entre variáveis (DENCKER, 1998).

\section{RESULTADOS E DISCUSSÕES}

\section{Perfil dos Gestores}

No que se refere às características pessoais, acadêmicas e profissionais dos gestores públicos de esporte e de lazer, os dados revelaram a predominância total do sexo masculino (100\%), sendo $60 \%$ solteiros e $66,7 \%$ estavam na faixa etária de 26 a 40 anos. Os dados apresentados na Tabela 2 ainda demonstram que aproximadamente $73 \%$ dos gestores não possuem nível superior.

Os dados de estudo de revisão sistemática elaborados por (ZANATTA; FREITAS, CARELLI; COSTA, 2018) corroboraram com os dados da pesquisa em tela no que se refere à predominância do sexo masculino na gestão pública, indicando a necessidade de medidas urgentes de distribuição e ocupação das mulheres em cargos diretivos de instituições públicas em esporte e lazer. Além disso, nota-se que desde o governo de Fernando Henrique Cardoso até o atual governo, período de 1995 a 2020, as mulheres nunca ocuparam o cargo máximo de gestão do esporte e do 
lazer em nível federal, no caso específico do Ministério do Esporte ou Secretaria Especial do Esporte.

No cenário das experiências profissionais anteriores aos cargos de gestores, os dados da pesquisa apontaram que $26 \%$ dos participantes eram funcionários públicos e em torno de $74 \%$ não tinham experiências anteriores com o setor público.

Neste panorama, pode-se inferir que os gestores não possuem estabilidade nos cargos, visto que, geralmente, o executivo muda de 4 em 4 anos, modificando os recursos humanos da gestão. Por outro lado, é preciso reconhecer que o gestor esportivo precisa ser um profundo conhecedor do ambiente no qual atua, mas, para além disso, se faz necessário que ele articule uma gama de competências que devem ser colocadas em prática (QUINAUD; MAZZEI; MILAN; MILISTETD; NASCIMENTO, 2019).

Tabela 2 - Perfil dos gestores de esporte e de lazer dos 15 municípios do Litoral Sul da Bahia

\begin{tabular}{|c|c|}
\hline Variáveis & Perfil da amostra $(n=15)$ \\
\hline $\begin{array}{c}\text { Sexo: } \\
\text { Homens } \\
\end{array}$ & $15(100 \%)$ \\
\hline $\begin{array}{l}\text { Faixa etária: } \\
\text { De } 26 \text { a } 40 \text { anos } \\
\text { De } 41 \text { a } 60 \text { anos }\end{array}$ & $\begin{array}{l}10(66,7 \%) \\
05(33,3 \%)\end{array}$ \\
\hline $\begin{array}{c}\text { Estado civil: } \\
\text { Solteiro(a) } \\
\text { Casado(a) } \\
\end{array}$ & $\begin{array}{l}09(60 \%) \\
06(40 \%)\end{array}$ \\
\hline $\begin{array}{c}\text { Grau de escolaridade: } \\
\text { Ensino Fundamental Completo } \\
\text { Ensino Médio Completo } \\
\text { Superior Incompleto } \\
\text { Superior Completo } \\
\end{array}$ & $\begin{array}{l}02(13,3 \%) \\
07(46,7 \%) \\
02(13,3 \%) \\
04(26,7 \%) \\
\end{array}$ \\
\hline $\begin{array}{c}\text { Ocupação principal (antes do mandato) } \\
\text { Estudante } \\
\text { Funcionário público } \\
\text { Empresário } \\
\text { Autônomo } \\
\text { Outro } \\
\end{array}$ & $\begin{array}{l}02(13,3 \%) \\
04(26,7 \%) \\
01(06,7 \%) \\
07(46,7 \%) \\
01(06,7 \%) \\
\end{array}$ \\
\hline $\begin{array}{c}\text { Tempo de prática/vivência em esporte e/ou lazer } \\
\text { De } 0 \text { a } 5 \text { anos } \\
\text { De } 5 \text { a } 10 \text { anos } \\
\text { De } 10 \text { a } 15 \text { anos } \\
\text { De } 15 \text { a } 20 \text { anos } \\
\text { Acima de } 20 \text { anos } \\
\end{array}$ & $\begin{array}{c}02(13,3 \%) \\
02(13,3 \%) \\
01(06,7 \%) \\
04(26,7 \%) \\
06(40 \%) \\
\end{array}$ \\
\hline $\begin{array}{c}\text { Tempo de atuação na gestão de esporte e lazer } \\
\text { De } 0 \text { a } 5 \text { anos } \\
\text { De } 15 \text { a } 20 \text { anos }\end{array}$ & $\begin{array}{l}13(86,7 \%) \\
02(13,3 \%)\end{array}$ \\
\hline
\end{tabular}

Fonte: Dados da pesquisa (2019).

Adicionalmente, outra questão que reforça a tese sobre o critério da indicação política para os cargos de gestores de esporte e lazer em contraposição à competência técnica pode ser observada 
no quesito nível de escolaridade, uma vez que apenas $26,7 \%$ dos participantes da pesquisa possuem ensino superior completo e, entre eles, somente um com graduação em Educação Física. Os resultados divergem de outro estudo realizado com 12 gestores de esporte de municípios pertencentes à União dos municípios da Média Sorocabana do Estado de São Paulo (UNMES), em que apenas 1 dos entrevistados não cursou ensino superior, 1 era graduado em Ciências Biológicas e 1 em Direito, sendo os outros 9 participantes graduados em Educação Física, representando 75\% dos participantes (SANTOS; FREIRE; BASTOS; MAZZEI, 2019).

Nesse panorama, pensando na importância da formação inicial em Educação Física para os gestores de esporte e lazer, os saberes acadêmicos, pessoais e profissionais poderão qualificar o potencial administrativo dos gestores, na consolidação de habilidades humanas e técnicas (QUINAUD; MAZZEI; MILAN; MILISTETD; NASCIMENTO, 2019). Por outro lado, pode-se notar que todos os gestores entrevistados possuem saberes advindos das experiências com as atividades esportivas e de lazer como ex-atletas ou praticantes, o que não significa necessariamente que possuam habilidades e competências técnicas para compreensão do papel dos órgãos como mobilizadores de políticas públicas de esporte e de lazer.

Obviamente que toda a responsabilidade da gestão do esporte e do lazer não deva se debruçar somente sobre a formação inicial em Educação Física e nem que esse profisssional seja o único habilitado a trabalhar neste contexto. Entretanto, acredita-se que em virtude de se observar que este é o profissional mais encontrado exercendo a função de gestor esportivo, a iniciativa de melhor qualificá-lo durante o período da formação inicial poderá refletir em sua atuação e desenvolvimento neste contexto. Nesse sentido, os resultados da pesquisa apontam para a possibilidade de que a gestão de esporte e lazer tenha se pautado não pela competência técnica e sim por outros interesses. A prática observada não chega a ser uma novidade em nosso país, ao contrário, as indicações políticas, muitas vezes bem distantes do conhecimento técnico, possuem origem histórica e um nome específico, o clientelismo (CARVALHO, 1997).

Desta maneira, os resultados lançam luz sobre um cenário no qual a gestão técnica e competente do setor de esporte e lazer, no caso dos municípios analisados, parece estar longe do que se considera serem as melhores práticas, distante, portanto, dos estudos de Galindo (2005, p. 1) para quem "a gestão pública (entendida como gestão política por essência) necessita ser profissional e subsidiada pelos conhecimentos técnicos científicos de sua esfera de atuação", neste caso, principalmente a Educação Física.

Dos resultados ainda emergem indícios de que a estruturação dos órgãos/secretarias é pautada por uma forte influência dos grupos políticos locais, uma vez que o preenchimento desses cargos acontece por indicação (cargos comissionados), ou seja, há que se questionar se a frequência 
de apoio político envolvido na indicação vem acompanhada da devida competência técnica que o cargo requer. Além disso, os setores e as pessoas são modificados estruturalmente em cada município, diante do momento político vigente (SANTOS; FREIRE; BASTOS; MAZZEI, 2019).

A análise dos dados obtidos junto aos gestores de esporte e lazer dos municípios que compõem o Território Litoral Sul da Bahia enseja uma discussão em torno das competências necessárias para atuação no setor. Nesse sentido, o Quadro 1 elaborado por Quinaud et al. (2019) apresenta três dimensões consideradas fundamentais para a gestão esportiva, são elas: a competência técnica, a competência contextual e a competência comportamental.

Quadro 1 - Sistematização das competências do gestor esportivo de acordo com as dimensões de competência técnica, contextual e comportamental.

\begin{tabular}{|c|c|c|}
\hline Competência Técnica & Competência Contextual & Competência Comportamental \\
\hline - Elaborar projetos & - Conhecer o contexto & - Disciplina \\
- Elaborar orçamentos & - Planejamento & - Liderança \\
- Avaliar & - Tomada de decisão & - Valores \\
& - Solução de problemas & - Perseverança \\
& - Relações interpessoais & - Ética \\
& & - Respeito \\
& & - Confiança \\
& & - Paciência \\
& & - Responsabilidade \\
& & - Saber delegar \\
& & - Saber julgar \\
\hline
\end{tabular}

Fonte: Quinaud et al. (2019).

Do ponto de vista conceitual, as competências inerentes ao indivíduo configuram-se enquanto mobilização de conhecimentos, habilidades, atitudes, interesses para o desenvolvimento de atividades, vislumbrando possibilidade de aprender a aprender, comunicação, colaboração, resolução de problemas e conhecimento tecnológico (CHIAVETANO, 2009). Além disso, o conceito de competências encontra-se na mobilização de habilidades necessárias nas atividades da vida cotidiana, direcionadas para a organização, o planejamento, a administração, o envolvimento, o trabalho em equipe, a utilização de recursos tecnológicos, a resolução de problemas e a administração de ações voltadas à promoção da formação continuada (PERRENOUD, 2000).

No que tange às competências humanas e técnicas contextualizadas no Quadro 1, infere-se que os gestores públicos de esporte e de lazer, ao assumirem suas responsabilidades, necessitam de saberes relacionados às técnicas de gestão de pessoas e de materiais e às atitudes de liderança, eficiência e eficácia nos processos de gestão e elaboração de projetos para a captação de recursos, tendo como fim a materialização de políticas públicas que atendam aos anseios dos munícipes (MIRANDA; FILHO; SILVA; FIGUEIRÊDO, PEDROSO, 2017). Além disso, ressalta-se o respeito 
aos princípios da administração pública, preconizados na Constituição Federal, relacionados à legalidade, impessoalidade, moralidade, publicidade e eficiência (BRASIL, 1998).

Desta maneira, os gestores públicos de esporte e lazer deverão desenvolver competências técnicas, humanas e acadêmicas. Em outras palavras, acredita-se no perfil de um profissional que esteja atento às políticas públicas. Sendo assim, uma atitude de enfrentamento dos problemas públicos, que possuem intencionalidades e tratam do conteúdo concreto e do conteúdo simbólico das decisões políticas, é de extrema relevância no processo de construção e execução de ações com o intuito de buscar resoluções que sejam coletivamente relevantes (SECCHI, 2013).

De outro modo, para que ações sejam garantidas, torna-se imprescindível que os governos elejam suas prioridades e garantam o financiamento das políticas públicas, o que não se tem realizado nos últimos anos no Brasil, nos estados e respectivos municípios (CASTRO; SCARPIN; SOUZA, 2020). Sendo assim, precisa-se pensar em formação de pessoas para a gestão conforme suas competências e as condições objetivas de trabalho efetivo para proposição e execução de ações públicas inclusivas de esporte e de lazer, enquanto direitos constitucionais dos brasileiros e brasileiras (AMARAL; RIBEIRO; SILVA, 2014).

\section{CONSIDERAÇÕES FINAIS}

A análise dos dados nos remete à necessidade de uma maior reflexão em torno das competências necessárias para atuação no setor. Ao analisarmos o perfil dos gestores responsáveis pelas políticas públicas de esporte e lazer dos 15 municípios do Território de Identidade Litoral Sul da Bahia, identificou-se que a competência técnica para o cargo segue sendo o foco de interferências políticas. A julgar pelos dados obtidos durante a pesquisa, verificou-se que o critério de escolha dos gestores pauta-se sobretudo pela afinidade político-partidária e não pela competência técnica para a gestão do setor. Mais do que um mero detalhe, acredita-se que este cenário esteja se constituindo em um entrave no processo de efetivação das ações de esporte e lazer na região.

A partir dos resultados foi possível observar que os saberes dos gestores são predominantemente advindos das experiências com as atividades esportivas e de lazer, o que não significa necessariamente que possuam habilidades e competências técnicas para compreensão do papel dos órgãos como mobilizadores de políticas públicas de esporte e de lazer. Dessa maneira, os resultados lançam luz sobre a necessidade de que a indicação dos profissionais seja subsidiada por conhecimentos técnicos e científicos, o que representa um desafio, especialmente em função dessas práticas estarem enraizadas no processo político brasileiro. 
Sabemos que o gestor é um dos atores principais no processo de efetivação das políticas públicas. Sendo assim, acreditamos que havendo um profissional qualificado à frente da gestão pública, provavelmente o setor ou órgão de esporte e lazer poderá planejar ações eficazes e eficientes, mesmo diante da precarização do orçamento que geralmente estes setores possuem desde a esfera federal, estadual até a municipal. Neste sentido, defendemos a necessidade de pessoas com a competência técnica, a competência contextual e a competência comportamental, para atuarem na perspectiva de pensar e executar políticas públicas de lazer e de esporte inclusivas.

Contudo, infelizmente no Brasil essa função vem sendo geralmente exercida por gestores que não dominam conhecimentos específicos de gestão ou mesmo por administradores que não possuem conhecimentos suficientes na área da Educação Física (MOCSÁNYI; BASTOS, 2005; MAZZEI; ROCCO JÚNIOR, 2017).

Com relação aos limites da pesquisa, cabe destacar o processo de coleta de dados, falta de informações nos sites das prefeituras, dificuldades de acesso aos dados e às pessoas responsáveis pelos setores de esporte e de lazer.

Infelizmente, na maioria dos municípios analisados, é notável a forma secundária como o setor de esporte e lazer (direitos assegurados pela Carta Constitucional de 1988) é pensado pela gestão municipal, sendo seu alcance curto, sua importância bastante limitada, muito distante de qualquer padrão minimamente aceitável no que se refere a uma proposta de democratização de acesso. Dito de outra maneira, ainda há muito por se fazer e talvez haja justamente na aproximação entre a universidade pública e os municípios um caminho privilegiado para se travar este debate, no sentido da integração ensino, serviço e comunidade.

Apesar de a intenção do presente estudo não ser discutir as diferenças entre os municípios, foi possível perceber que existem diferenças significativas na gestão deles, o que pode suscitar a necessidade de análises individuais.

\section{REFERÊNCIAS}

AMARAL, Silvia Cristina Franco; RIBEIRO, Olívia Cristina Ferreira; SILVA, Dirceu Santos. Produção científico-acadêmica em políticas públicas de esporte e lazer no Brasil. Motrivivência, Florianópolis, v. 26, n. 42, p. 27-40, jul. 2014. Disponível em: https://periodicos.ufsc.br/index.php/motrivivencia/article/view/2175-8042.2014v26n42p27. Acesso em: 19 nov. 2020.

ATHAYDE, Pedro; MASCARENHAS, Fernando; SALVADOR, Evilásio. Primeiras aproximacões de uma análise do financiamento da política nacional de esporte e lazer no Governo Lula. Revista Brasileira de Ciências do Esporte, v. 37, n. 1. 2015. Disponível em: https://www.scielo.br/pdf/rbce/v37n1/0101-3289-rbce-37-01-0002.pdf. Acesso em: 19 nov. 2020. 
BAHIA. Perfil dos Territórios de Identidade/Superintendência de Estudos Econômicos e Sociais da Bahia. Salvador: SEI, 2015. Disponível em:

https://www.sei.ba.gov.br/index.php?option $=$ com content\&view $=$ article\&id=2000\&Itemid $=284$. Acesso em: 19 nov. 2020.

BETTIN, Everton Burlamarque; PEIL, Luciana Marins Nogueira; MELO, Marcelo Paula. Políticas públicas municipais de esporte, lazer e espaços públicos em Pelotas-RS na gestão 2009-2012. Pensar a Prática, v. 21, n. 1, 2018. Disponível em: https://www.revistas.ufg.br/fef/article/view/38544 . Acesso em: 19 nov. 2020.

BRASIL. Ministério da Cidadania. 2020. Disponível em:

https://www.gov.br/cidadania/pt-br/noticias-e-conteudos/esporte. Acesso em: 20 set. 2020.

BRASIL. Constituição (1998). Constituição da República Federativa do Brasil: promulgada em 5 de outubro de 1998: atualizada até a Emenda Constitucional n 20, de 15-12-19.

CARNEIRO, Fernando Henrique Silva; ATHAYDE, Pedro Fernando Avalone; MASCARENHAS, Fernando. Era uma vez um ministério do esporte...: seu financiamento e gasto nos governos Lula, Dilma e Temer. Motrivivência, Florianópolis, v. 31, n. 60, p. 01-22, outubro/dezembro, 2019. Disponível em: https://periodicos.ufsc.br/index.php/motrivivencia/article/view/2175-8042.2019e65541. Acesso em: 19 nov. 2020.

CARVALHO, José Murilo de. Mandonismo, Coronelismo, Clientelismo: Uma Discussão Conceitual. Dados, Rio de Janeiro, v. 40, n. 2, 1997.

CASTRO, Suélen Barboza Eiras; SCARPIN, Jorge Eduardo; SOUZA, Doralice Lange. Ciclo orçamentário e prioridades das políticas federais para o esporte e lazer no Brasil (2004-2011). Revista Brasileira de

Educação Física e Esporte, v. 33, n. 4, p. 531-549, jun. 2020. Disponível em:

https://www.revistas.usp.br/rbefe/article/view/170588. Acesso em: 19 nov. 2020.

CHIAVENATO, Idalberto. Planejamento, recrutamento e seleção de pessoal: como agregar talentos à empresa. Manole, 2009.

DENCKER, Ada de Freitas Maneti. Métodos e técnicas de pesquisa em turismo. Futura, São Paulo, v. 10, n. 2, 1998.

EWERTON, Andréa Nascimento; MATIAS, Wagner Barbosa. Gestão Estratégica das Experiências de Lazer na Esfera Federal. In: AZEVÊDO, Paulo Henrique; BRAMANTE, Antônio Carlos (Org.). Gestão estratégica das experiências de lazer. Curitiba: Appris, 2017.

GALINDO, Alexandre Gomes. Esporte e lazer municipal: reflexões sobre as bases do planejamento e gestão pública. Revista do Plano Diretor Participativo do Município de Santana-AP, v. 1, n. 1, p. 49-62, 2005. Disponível em: https://mid.curitiba.pr.gov.br/2015/00160848.pdf. Acesso em: 19 nov. 2020.

GIL, Antônio Carlos. Como elaborar Projetos de Pesquisa. 5. ed. São Paulo: Atlas, 2010.

LINHALES, Meily Assbú. Políticas Públicas para o esporte no Brasil. In: Anais do X Congresso Brasileiro de Ciências do Esporte, Goiânia: GEP. 1997, p. 378.

MAZZEI, Leandro Carlos; ROCCO JÚNIOR, Ary José. Um ensaio sobre a Gestão do Esporte: um momento para a sua afirmação no Brasil. Revista de Gestão e Negócios do Esporte, São Paulo, v. 2, n. 1, p. 96-109, 2017. Disponível em:

https://www.researchgate.net/publication/318205167 Um ensaio sobre a Gestao do Esporte um moment o_para_a_sua_afirmacao_no_Brasil. Acesso em: 19 nov. 2020. 
MEZZADRI, Fernando Marinho; SILVA, Marcelo Moraes; FIGUERÔA, Mello Katiuscia. Desenvolvimento de um método para as pesquisas em políticas públicas de esporte no Brasil: uma abordagem de pesquisa mista. Motrivivência, Florianópolis, v. 27, n. 44, 2015. Disponível em:

https://periodicos.ufsc.br/index.php/motrivivencia/article/view/2175-8042.2015v27n44p49. Acesso em: 20 nov. 2020.

MIRANDA, Yves de Holanda Batista de; FILHO, Marcos Antônio; SILVA, Victor Henrique Rodrigues; FIGUEIRÊDO, Juliett de Medeiros Correia; PEDROSO, Carlos Augusto Mulatinho de Queiroz. Análise acerca das competências necessárias para a atuação profissional do Gestor Esportivo. Pensar a Prática, v. 20, n. 3, 29 set. 2017. Disponível em: https://www.revistas.ufg.br/fef/article/view/44154. Acesso em: 20 out. 2020 .

MOCSÁNYI, Vinícius; BASTOS, Flávia da Cunha. Gestão de pessoas na administração esportiva:

considerações sobre os principais processos. Revista Mackenzie de Educação Física e Esporte, São Paulo, v. 4, n. 4, p. 55-69, 2005. Disponível em:

https://www.mackenzie.br/fileadmin/OLD/47/Graduacao/CCBS/Cursos/Educacao_Fisica/REMEFE-4-4-200 5/art4 edfis4n4.pdf. Acesso em: 19 nov. 2020.

PERRENOUD, Philippe. Dez novas competências para ensinar. Porto Alegre: Artes Médicas Sul, 2000.

QUINAUD, Ricardo Teixeira; MAZZEI, Leandro Carlos; MILAN, Fabrício João; MILISTETD, Michel; NASCIMENTO, Juarez Vieira do. Gestores do esporte: reflexões sobre sua formação e desenvolvimento profissional. Pensar a Prática, v. 22, 25 abr. 2019. Disponível em:

https://revistas.ufg.br/fef/article/view/52188. Acesso em: 20 out. 2020.

SANTOS, Flávia da Cruz; AMARAL, Silvia Cristina Franco. Sobre lazer e políticas sociais: questões teórico-conceituais. Pensar a Prática, v. 13, n. 3, 21 dez. 2010. Disponível em:

https://www.revistas.ufg.br/fef/article/view/10175. Acesso em: 19 nov. 2020.

SANTOS, Marco Aurélio Gonçalves Nóbrega; FREIRE, Elisabete dos Santos; BASTOS, Flávia da Cunha; MAZZEI, Leandro Carlos. A percepção dos gestores sobre os objetivos do esporte nos municípios.

Cuadernos de Psicología del Deporte, v. 19, n. 3, p. 179-189. 2019. Disponível em: http://scielo.isciii.es/pdf/cpd/v19n3/1578-8423-CPD-19-3-00179.pdf. Acesso em: 19 nov. 2020.

SECCHI, Leonardo. Políticas Públicas: conceitos, esquemas de análise, casos práticos. 2. ed. São Paulo: Cengage Learning, 2013.

ZANATTA, Thaís Camargos; FREITAS, Miranda de; CARELLI, Filipe Gomide; COSTA, Israel Teoldo da. O perfil do gestor esportivo brasileiro: revisão sistemática da literatura. Movimento, Porto Alegre, v. 24, n. 1, p. 291-304, jan./mar. de 2018. Disponível em: https://seer.ufrgs.br/Movimento/article/view/73803. Acesso em: 19 nov. 2020. 


\section{NOTAS DE AUTOR}

AGRADECIMENTOS - Agradecemos ao Centro de Desenvolvimento de Pesquisas em Políticas de Esporte e Lazer da Rede Cedes - CDPPEL" que realizou o projeto original intitulado "Políticas Públicas de Esporte e Lazer e Territórios de Identidade da Bahia" financiado pelo Ministério do Esporte (Portaria $n^{\circ} 3$, de 1.10.15) e a Mariana Santos Singer, que auxiliou na coletada de dados no início do Projeto. Agradecemos ainda ao Programa de Iniciação Científica da UESC e ao Programa de Iniciação Científica da FAPESB, pela concessão de bolsas aos discentes envolvidos da pesquisa.

\section{CONTRIBUIÇÃO DE AUTORIA}

Concepção do manuscrito: M. A. Ávila, F. E. F. Marta, C. S. Bahia

Coleta de dados: L. M. A. Levita, C. C. V. Santos

Análise de dados: L. M. A. Levita, C. C. V. Santos, M. A. Ávila, F. E. F. Marta, C. S. Bahia

Discussão dos resultados: L. M. A. Levita, C. C. V. Santos, M. A. Ávila, F. E. F. Marta, C. S. Bahia

Produção do texto: M. A. Ávila, F. E. F. Marta, C. S. Bahia

Revisão e aprovação: M. A. Ávila

FINANCIAMENTO - Universidade Estadual de Santa Cruz-UESC, pela concessão de bolsa de iniciação científica. Fundação de Amparo à Pesquisa do Estado da Bahia-FAPESB, pela concessão de bolsa de iniciação científica.

\section{CONSENTIMENTO DE USO DE IMAGEM - Não se aplica}

APROVAÇÃO DE COMITÊ DE ÉTICA EM PESQUISA - Todos os protocolos da pesquisa aconteceram com base nos trâmites do Comitê de Ética em Pesquisa com Seres Humanos da Universidade Estadual de Santa Cruz, sob o número CAEE: 71324717.0.0000.5526. Aprovado em $10 / 08 / 2017$.

CONFLITO DE INTERESSES - Não existem conflitos de interesses financeiros ou pessoais entre os autores, os revisores e os editores.

\section{LICENÇA DE USO}

Os autores cedem à Motrivivência - ISSN 2175-8042 os direitos exclusivos de primeira publicação, com o trabalho simultaneamente licenciado sob a Licença Creative Commons Attribution Non-Comercial ShareAlike (CC BY-NC SA) 4.0 International. Esta licença permite que terceiros remixem, adaptem e criem a partir do trabalho publicado, desde que para fins não comerciais, atribuindo o devido crédito de autoria e publicação inicial neste periódico desde que adotem a mesma licença, compartilhar igual. Os autores têm autorização para assumir contratos adicionais separadamente, para distribuição não exclusiva da versão do trabalho publicada neste periódico (ex.: publicar em repositório institucional, em site pessoal, publicar uma tradução, ou como capítulo de livro), com reconhecimento de autoria e publicação inicial neste periódico, desde que para fins não comerciais e compartilhar com a mesma licença.

\section{PUBLISHER}

Universidade Federal de Santa Catarina. Programa de Pós-Graduação em Educação Física. LaboMídia - Laboratório e Observatório da Mídia Esportiva. Publicado no Portal de Periódicos UFSC. As ideias expressadas neste artigo são de responsabilidade de seus autores, não representando, necessariamente, a opinião dos editores ou da universidade. 


\section{EDITORES}

Mauricio Roberto da Silva, Giovani De Lorenzi Pires, Rogério Santos Pereira.

\section{EDITOR DE SEÇÃO}

Bianca Poffo.

\section{REVISÃO DO MANUSCRITO E METADADOS}

João Caetano Prates Rocha; Keli Barreto.

\section{HISTÓRICO}

Recebido em: 19 de outubro de 2020.

Aprovado em: 10 de dezembro de 2020. 